\title{
Public Health Emergency Operations Center - A critical component of mass gatherings management infrastructure
}

\author{
Habidah Elachola ${ }^{1}$, Jaffar A Al-Tawfiq ${ }^{2,3}$, Abdulhafiz Turkestani ${ }^{4}$, Ziad A Memish ${ }^{1,5}$ \\ ${ }^{1}$ Ministry of Health, Riyadh, Kingdom of Saudi Arabia \\ 2 Johns Hopkins Aramco Healthcare, Dhahran, Kingdom of Saudi Arabia \\ 3 Indiana University School of Medicine, Indianapolis, IN, United States \\ ${ }^{4}$ Makkah regional Health Directorate, Ministry of Health, Makkah, Saudi Arabia \\ ${ }^{5}$ College of Medicine, Alfaisal University, Riyadh, Saudi Arabia
}

\begin{abstract}
Mass gatherings (MG) are characterized by the influx of large numbers of people with the need to have infrastructural changes to support these gatherings. Thus, Public Health Emergency Operations Center (PHEOC) is critical management infrastructure for both the delivery of public health functions and for mounting adequate response during emergencies. The recognition of the importance of PHEOC at the leadership and political level is foundational for the success of any public health intervention during MG. The ability of the PHEOC to effectively function depends on appropriate design and infrastructure, staffing and command structure, and plans and procedures developed prior to the event. Multi-ministerial or jurisdictional coordination will be required and PHEOC should be positioned with such authorities. This paper outlines the essential concepts, elements, design, and operational aspects of PHEOC during MG.
\end{abstract}

Key words: Mass gatherings; Hajj; Emergency Operations Center.

J Infect Dev Ctries 2016; 10(8):785-790. doi:10.3855/jidc.8332

(Received 04 March 2016 - Accepted 03 May 2016)

Copyright (C) 2016 Elachola et al. This is an open-access article distributed under the Creative Commons Attribution License, which permits unrestricted use, distribution, and reproduction in any medium, provided the original work is properly cited.

\section{Introduction}

Public health is increasingly becoming an essential component of the management structure of mass gatherings (MG). The management of public health functions during $\mathrm{MG}$, therefore, requires unique management capabilities--the establishment of public health emergency operations centers (PHEOC). The effectiveness of the PHEOC was established previously [1]. While the term PHEOC or command center in public health is relatively new, the principles of emergency management have been applied during the Hajj pilgrimage for decades as the health risks during mass gatherings became evident. In the past few decades, the Hajj Health Command Center has been formalized. For the first time, in 2005, the International Health Regulations developed by the World Health Organization, required countries to "develop, strengthen, and maintain, the capacity to respond promptly and effectively to public health risks and emergencies of international concern", and in 2013 developed guidelines for the establishment of PHEOCs [2-4]. The new concept of PHEOC as a critical element of public health preparedness [5] has been strengthened recently by emerging global threats including the 2014 West Africa Ebola Crisis, the related global response, and the Global Health Security Agenda [4,6-8]. Based on the authors' experience in the establishment of the Hajj PHEOC, exposure to other major public health PHEOCs, and drawing from emerging discussions on PHEOCs, in this paper, we outline the rationale, design considerations, and organizational and operational aspects of PHEOC during mass gatherings.

\section{Rationale for PHEOC during mass gatherings}

During mass gatherings, the present health and support services in the host country may be adequate to deal with existing diseases including the occurrence of outbreaks. Such capacities vary depending on the development trajectory of countries. However, due to various reasons, the influx of large numbers of people during MGs and the need to adjust infrastructures may add burden in the ability to detect emerging health issues and carry out an effective response. First, regular public health functions are carried out on a 5 or 6 day per week schedule with regular working hours whereas mass gathering public health functions require 24/7 (24 
hours a day -7 days a week) operation. Second, in nonMG setting, separate but interconnected administrative units (ministries) implement various components of a response at their own pace matching their organizational capacity and operating procedures. There may be very limited interaction between public health officials and law enforcement during the nonMG period. During an MG, however, due to the brevity of time and scale of response, unlike all other functions of traditional health sector, collaboration and partnerships with multiple ministries beyond the authority of the health ministry is required and under a single command structure. Third, due to the emergency nature of the event, practical aspects of public health tools used during mass gatherings may differ from that used in regular settings. Fourth, international $\mathrm{MG}$ creates additional challenges: a sudden increase in more culturally and linguistically diverse population with different disease epidemiology — management capacity for which may not exist in the regular health system. Finally, in the regular (non-MG) health care system in many developing countries, PHEOC is a new concept and most countries may not have experience with the establishment or use of a PHEOC.

Other key challenges intrinsic to MG include high political visibility and political pressure (a non-MG health care delivery infrastructure is generally far removed from the political radar), and warnings and hoaxes requiring appropriate political and media responses. A PHEOC becomes the staging area for the required multi-agency planning and response.

\section{Definitions}

\section{Emergency management}

The discipline dealing with the assessment, reduction, and avoidance of excessive risk events arising from natural, human-generated, or technological causes through an organized response.

\section{Emergency operations center (EOC)}

EOC is also known as command centers, situation rooms, or crisis management centers [9]. EOC is a physical or virtual centers where an organization coordinate response, recovery actions and resources during an emergency or a disaster [2].

\section{Incident}

"An occurrence either human caused or by natural phenomena, that requires action to prevent or minimize loss of life or damage to property and/or natural resources" [10].
The Incident Command System (ICS)

is the multi-jurisdictional or multi-disciplinary response system dealing with emergency situations $[11,12]$.

\section{Essential components of emergency management:}

- PHEOC design principles, infrastructure, equipment and supplies

- PHEOC staff and field responders

- Policies, plans and procedures.

Although in an emergency situation, event specific incident management systems are set up instantly, the development trajectory of a permanent preparedness capacity generally follows a stepped approach. The first priority for establishment of a permanent preparedness infrastructure is political engagement, information sharing, and technical discourse among policy makers. These activities can be complemented by development of systems that includes policies and guidelines, establishment of infrastructure including physical space and communication redundancies, and manpower development $[13,14]$. Once these steps are realized preparedness systems can be operationalized.

\section{Principles of PHEOC design}

PHEOC is an important structure to coordinate activities during either small emergencies or large-scale disasters [15]. PHEOC is designed to be operational during emergencies including at a time when normal operational capacity is non-existent as experienced during Hurricane Katrina in the United States [16-18]. Further, a perfectly established PHEOC may suffer from the impact of another event or emergencies such as aftershocks or flooding after an earthquake. These challenges are the rationale for the five primary considerations for the design and construction of a new Emergency Operations Center: Survivability, Redundancy, Communications, Flexibility and Open Architecture, and Security [19]. These plans are imperative irrespective of the temporary nature of the PHEOC during a mass gathering.

\section{Survivability}

It is critical that an PHEOC created for a mass gathering remains operational including during a natural catastrophe, accidents, or terrorist events when the PHEOC functions are most at need. It is important to have any PHEOC operation to be located at another facility with the same capacity and technology to avoid any PHEOC disadvantage. The New York City Office of Emergency Management (OEM) had this experience 
when their PHEOC was affected during the World Trade Center attack [19].

Although we may not have a choice of locations, ideally, the PHEOC should be located in a safe building to avoid any hazard [19]. There should be separation from highways, railroads, pipelines, hazardous material sites, and the like. It is important to examine the location of the PHEOC and to take necessary measures protecting the facility from natural and artificial disasters, and from airborne hazards.

\section{Redundancy}

Redundancy is an important factor for the center survivability. However, having multiple backup systems is usually challenging due to financial constraints. In an electric power surge in 2003, there was an increase in the human exposure and information calls in a poison center calling for a communication system redundancy, and an increase in the back-up power supply [20]. In New York, the availability of resources served as an excellent substitute for redundancy of personnel, equipment and space [21]. PHEOC operations are technology dependent and electronic systems require air-conditioning to keep them functioning.

Therefore, the availability of generators to assure continuity in electricity supply is important. Irrespective of the existence of electronic documents, paper copies of some essential documents including standard operating procedures, emergency medication descriptions, and telephone numbers of core staff should be prepared and made available. Essential supplies such as fuel, water, and ready to eat meals are other supplies that should be available. The optimal days for which supplies should be considered was suggested to be three days and might be as long as 7-10 days in the case of PHEOC catastrophic events. [19].

\section{Communications}

An important role of the PHEOC is to maintain clear and updated information about the incident or the disaster. Effective communication is mandatory to keep the public trust in the messages and in the function of the PHEOC [22]. Thus, multiple communication systems are required to meet this objective such as phones, and radio systems. As the center of communication in the PHEOC may also be affected and get lost [23]. An advanced WiFi-based network was designed to meet the needs of karge scale medical response system [24]. It is important to integrate the best communication practices in the PHEOC [25]. The use of electronic based system for data collection is more efficient than paper-based systems and reduce latency while increasing the quality of information [26]. During the 2012 Hajj, digital pens were introduced to convert data from conventional paper-based system into digitalized display $[27,28]$. The information technology system captures data, analyzes the data and displays them at the Hajj Command and Control Center [27].

\section{Flexibility and Open Architecture}

As much as possible, given the need for surge capacity, it is important to anticipate surge in staffing and technology in the design. Given the rapid changes in technology, design flexibility is needed in case of increased operations and the addition of new technology [9]. Open architecture is the norm for PHEOC, so that space can be configured based upon needs. Also, open architecture promotes instant inperson communication among staff during an event.

\section{Security}

PHEOCs may be primary or secondary targets for terror attacks or may be involved in collateral damage $[12,23]$. Also, given that PHEOC may be the only entity associated with the government that functions, PHEOC may be target for mob violence in times of crisis. Layered levels of security allow operationalization security to match threat levels. Basic level of security may be in place when the threat level is low and increased incrementally to match threat levels. It is important to have a secure access control utilizing fences, electronic gates, security checkpoints and biometric devices.

\section{Physical layout of PHEOC}

The size of PHEOCs may vary considerably by the size of the mass gathering event. Irrespective of the space dimensions, it would be useful to consider the basic PHEOC layout approaches including the Boardroom, Mission Control, Marketplace, Bull's-Eye or Virtual models. The underlying philosophy of any lay out should be ease of function of an PHEOC- ease of communication (technological and in person), easy assembly or convening of multidisciplinary teams, ease of sharing coordination information, and concentrate command structure activities in a visibly manageable location [8,14,29-31] For example, if watch functions, logistics, and field operations are accommodated in independent buildings or floors or separated by divisions, coordination can take longer time than if it was in the same space. The layout of the PHEOC room may take the form of a boardroom, mission control, 
marketplace or Bull's eye design. The different design indicates a selective indication. For example, board room design indicates a collaborative interactive design and is ideal when the group is small. The marketplace design allows that each small table be assigned a specific task.

Virtual arrangements may never be considered an alternative to a physical PHEOC, but could serve as a supplement enabling surge capacity, or while a physical PHEOC is in development. The challenges include the reliability and security of technology, and the difficulty in managing group processes online.

\section{Staffing of PHEOC}

The generic organogram of PHEOC is designed to enable the three generally accepted concept of operations: a single decision making authority (strategy and policy), to operationalize (coordination), implementation (tactical) of response that matches the scale and scope of the event (Figure 1). The basic model can be expanded to accommodate all relevant disciplines without the need to create additional leadership tracks that becomes necessary. The roles and responsibilities of key sections of the PHEOC (Table 1) enable the incident command to optimize the response and communication plan. PHEOC may not be responsible for executing all the elements of the response that is required (for example border control); however, PHEOC provides the guidance. Therefore, PHEOC should have the authority to effectively work with various ministries or administrative units to assure that all response activities are implemented [22,32-34]. Science response sections may be needed if faced with emerging disease threats or other events of significance that are beyond the general epidemiology of routine mass gathering related health consultations. The science team may include subject matter experts from epidemiology and surveillance, laboratory, disease specialties (for example, infectious diseases,
Figure 1. Structure of Public Health Emergency Operations Center (PHEOC)

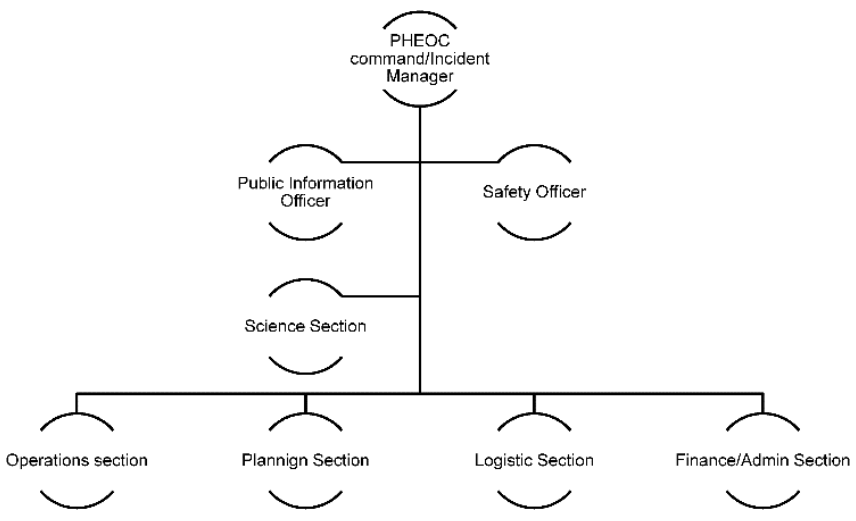

environmental and occupational), medical care and medical countermeasures, and international disease control coordination. Together, these experts can provide technical guidance to the incident manager on scientific interventions, prepare and present data for the incident management plan, and assure scientific basis of response. Delivery of non-medical measures is normally delegated to respective ministries such as the defence or police sector for crowd control and distribution of essential commodities.

Public information is critical to response management $[13,25,26,32]$. The public health information officer is charged with determining current media presence and establishing contact with the media, determine and comply with public information processes, converting scientific information to a format that is useful to the media for public release, and providing proactive and regular press releases and media briefings that can help reduce rumors and misassumptions by the public.

The safety officer role is to identify threats to the response infrastructure, identifying and monitoring hazardous situations associated with the event or the

Table 1. Functions of core leadership of an emergency operations center

\begin{tabular}{lll}
\hline \multirow{2}{*}{ Function } & \multicolumn{2}{l}{ Description } \\
\hline \multirow{2}{*}{ Incident Command / EOC Manager } & - & Establishes incident objectives, strategies, and priorities. \\
\multirow{2}{*}{ Operations } & - & Assumes overall responsibility for the incident. \\
& - & Determines tactics and resources for achieving objectives. \\
Planning & Directs the response. \\
& - & Collects and analyzes information. \\
Logistics & - & Tracks resources. \\
\multirow{2}{*}{ Finance/Administration } & Maintains documentation. \\
\hline
\end{tabular}


response, and ensure that adequate levels of protective equipment are available and being used properly.

\section{Policies, plans and procedures}

Documents that should be prepared in advance prior to the event include:

- Emergency management plans

- Procedures

An emergency event is not the time to prepare an emergency management plan. Emergency management plans should be prepared prior to a mass gathering and made available to all staff members at the PHEOC, generally included in the share drives of the computers they are assigned to. Availability of finalized contingency plans and functional plans as their appendices can help avoid panic and confusion. Functional plans should offer continuity measures, address cross-cutting issues including communications and vulnerable population challenges, and mission specific as to mitigation or risk and recovery of normalcy. Procedures are documents outlining how to consistently execute tasks and may be called standard operating procedures [SOP]. They should cover, purpose, scope, responsibilities and job descriptions of staff, tasks and standards of performance, and checklists for various activities $[1,14]$.

Documents that are prepared during events needing emergency operation center activation include:

- Incident action plans

- Situation reports

Incident action plans identify tactical implementation steps for a response for a defined operational period. As a minimum, they contain, critical situation updates, response strategies, response tactics, resources, logistics procedures, and incident map. Situation reports are documents that provide situational awareness to leadership and stakeholders. These reports document response actions taken, current epidemiological information, and proposed activities until the next reporting period.

\section{Conclusion}

Significant amount of advocacy and engagement would be needed to internalize the concept of PHEOC as a permanent institution within the $\mathrm{MOH}$ frame work, especially for mass gatherings. An PHEOC at mass gatherings can only be as strong as the surveillance and laboratory systems in the country and at the event and the ability of the PHEOC to effectively liaise with these entities on a timely manner [35]. It is also important that such PHEOC coordinate activities nationally, locally and internationally to achieve the desired goals [33].
During the SARS epidemic, mobilization of teams from the USA provided assistance to the involved countries [34]. Therefore, a good understanding of the rationale and functions of the PHEOC and directives to enhance the operational aspects is critical among all entities of the administrative sectors of a mass gathering. PHEOCs are only a formalized and developed staging area to manage a crisis and only functions well if the support infrastructure is available. Established PHEOCs improves the capacity of mass gathering management to effectively respond to public health crisis that unpredictably threatens to overwhelm routine capabilities [27,28,33,34,36,37].

\section{References}

1. Scalon J (1994) The Role of EOCs in Emergency Management: A Comparison of American and Canadian Experience. Int J Mass Emerg Disasters 12: 51-75.

2. World Health Organization (2013) A Systematic Review of Public Health Emergency Operations Centers [EOC], Geneva, Word Health Organization. http://apps.who.int/iris/bitstream/10665/99043/1/WHO_HSE_ GCR_2014.1_eng.pdf. Accessed 15 April 2016

3. World Health Organization (2006) Managing Health Emergencies: A Guide for Establishing, Operating and Evaluating An Emergency Operations Centre. http://www.pacificdisaster.net/pdnadmin/data/original/WHO 2006_Managing_Health_Emergencies_EOC.pdf. Accessed $1 \overline{5}$ April 2016

4. WHO (2005). International Health Regulations (IHR). Avilable http://apps.who.int/iris/bitstream/10665/43883/1/9789241580 410_eng.pdf. Accessed 15 April 2016

5. Gibson PJ, Theadore F, Jellison JB (2012) The common ground preparedness framework: a comprehensive description of public health emergency preparedness. Am J Public Health 102: 633-642. doi:10.2105/AJPH.2011.300546.

6. Preventio C for DC and Global health Security Agenda 2015. Available at http://www.cdc.gov/globalhealth/security/. Accessed 15 April 20167.

7. Papagiotas SS, Frank M, Bruce S, Posid JM (2012) From SARS to 2009 H1N1 influenza: the evolution of a public health incident management system at CDC. Public Health Rep 127: 267-274.

8. Centers for Disease Prevention and Control. Public health preparedness capabilities: national satndards for state and local planning 2011. Available at: http://www.cdc.gov/phpr/capabilities/dslr_capabilities_july.p df. Accessed 15 April 2016

9. Xu M, Li S-X (2015) Analysis of good practice of public health Emergency Operations Centers. Asian Pac J Trop Med 8: 6776 82. doi:10.1016/j.apjtm.2015.07.006.

10. USDA. Glossary n.d. Available at: http://www.usda.gov/wps/portal/usda/usdamobile?navid=HO MELANDICSGL. Accessed: 15 April 2016

11. Jensen J, Thompson S (2016) The Incident Command System: a literature review. Disasters 40: 158-182. doi:10.1111/disa.12135.

12. Adams EH, Scanlon E, Callahan JJ, Carney MT (2008) Utilization of an incident command system for a public health 
threat: West Nile virus in Nassau County, New York. J Public Health Manag Pract 16: 309-415. doi:10.1097/PHH.0b013e3181bb8392.

13. Aung E, Whittaker M (2013) Preparing routine health information systems for immediate health responses to disasters. Health Policy Plan 28: 495-507. doi:10.1093/heapol/czs081.

14. Mignone AT, Davidson R (2003) Public health response actions and the use of emergency operations centers. Prehosp Disaster Med 18: 217-219.

15. Moore S, Mawji A, Shiell A, Noseworthy T (2007) Public health preparedness: a systems-level approach. J Epidemiol Community Health 61: 282-286. doi:10.1136/jech.2004.030783.

16. Gramling C (2005) Hurricane Katrina. Riding out the storm. Science 309: 1657. doi:10.1126/science.309.5741.1657.

17. Greenough PG, Kirsch TD (2005) Hurricane Katrina. Public health response--assessing needs. N Engl J Med 353: 15441546. doi:10.1056/NEJMp058238.

18. Centers for Disease Control and Prevention (CDC) (2015). Hurricane Katrina response and guidance for health-care providers, relief workers, and shelter operators. MMWR Morb Mortal Wkly Rep 54: 877.

19. Holdeman E. EOC Design Considerations. Available at: http://www.disaster-resource.com/articles/08p_136.shtml. Accessed 4 July 2016

20. Klein KR, Herzog P, Smolinske S, White SR (2007) Demand for poison control center services "surged" during the 2003 blackout. Clin Toxicol (Phila) 45: 248-254. doi:10.1080/15563650601031676.

21. Kendra JM, Wachtendorf T (2003) Elements of resilience after the World Trade Center disaster: reconstituting New York City's Emergency Operations Centre. Disasters 27: 37-53.

22. Rebmann T, Carrico R, English JF (2008). Lessons public health professionals learned from past disasters. Public Health Nurs 25: 344-352. doi:10.1111/j.1525-1446.2008.00715.x.

23. Simon R, Teperman S (2001) The World Trade Center attack. Lessons for disaster management. Crit Care 5: 318-320.

24. Arisoylu M, Mishra R, Rao R, Lenert LA (2005) 802.11 wireless infrastructure to enhance medical response to disasters. AMIA Annu Symp Proc 1-5.

25. Covello VT (2003) Best practices in public health risk and crisis communication. J Health Commun 8 Suppl 1: 5-8; discussion 148-51. doi:10.1080/713851971.

26. Demchak B, Chan TC, Griswold WG, Lenert LA (2006) Situational awareness during mass-casualty events: command and control. AMIA Annu Symp Proc 905.

27. Memish ZA, Zumla A, Alhakeem RF, Assiri A, Turkestani A, Al Harby KD, Alyemni M, Dhafar K, Gautret P, Barbeschi M, McCloskey B, Heymann D, Al Rabeeah AA, Al-Tawfiq JA
(2014) Hajj: infectious disease surveillance and control. Lancet 383: 2073-2082. doi:10.1016/S0140-6736(14)60381-0.

28. Al-Tawfiq JA, Memish ZA (2014) Mass gathering medicine: 2014 Hajj and Umra preparation as a leading example. Int J Infect Dis 27: 26-31.

29. Keim M (2002) Developing a public health emergency operations plan: a primer. Pac Health Dialog 9: 124-129.

30. [No authors listed] (2012) Preparing routine health information systems for immediate health responses to natural disasters. Pac Health Dialog 18: 279-281.

31. Nelson C, Lurie N, Wasserman J (2007) Assessing public health emergency preparedness: concepts, tools, and challenges. Annu Rev Public Health 28: 1-18. doi:10.1146/annurev.pu.28.030607.100011.

32. Khorram-Manesh A, Hedelin A, Ortenwall P (2009) Regional coordination in medical emergencies and major incidents; plan, execute and teach. Scand J Trauma Resusc Emerg Med 17: 32. doi:10.1186/1757-7241-17-32.

33. Jones M, O'Carroll P, Thompson J, D'Ambrosio L (2008) Assessing regional public health preparedness: a new tool for considering cross-border issues. J Public Health Manag Pract 14:E15-22. doi:10.1097/01.PHH.0000333891.06259.44.

34. Posid JM, Bruce SM, Guarnizo JT, Taylor ML, Garza BW (2005) SARS: mobilizing and maintaining a public health emergency response. J Public Health Manag Pract 11: 208-15.

35. Yi H, Zheng'an Y, Fan W, Xiang G, Chen D, Yongchao H, Xiaodong S, Hao P, Mahany M, Keim M (2012). Public health preparedness for the world's largest mass gathering: 2010 World Exposition in Shanghai, China. Prehosp Disaster Med 27:589-94. doi:10.1017/S1049023X12001252.

36. King R V, North CS, Larkin GL, Downs DL, Klein KR, Fowler RL, Swienton RE, Pepe PE 1 (2010). Attributes of effective disaster responders: focus group discussions with key emergency response leaders. Disaster Med Public Health Prep 4:332-8. doi:10.1001/dmphp.D-09-00059R1.

37. Centers for Disease Control and Prevention (CDC) (2013)..CDC's Emergency Management Program activities worldwide, 2003-2012. MMWR Morb Mortal Wkly Rep 62:709-13.

\section{Corresponding author}

Prof. Ziad A Memish

College of Medicine, Alfaisal University \& Ministry of Health

P.O. Box 54146

Riyadh, 11514, Saudi Arabia

Phone: + 966505483515

FAX: +96611266464

Email: zmemish@yahoo.com.

Conflict of interests: No conflict of interests is declared. 